\title{
RELATION BETWEEN LEFT VENTRICULAR UNLOADING DURING ECMO AND DRAINAGE CATHETER SIZE ASSESSED BY MATHEMATICAL MODELING
}

\author{
Svitlana Strunina ${ }^{a, *}$, Jiri Hozman $^{a}$, Petr Ostadal $^{b}$ \\ ${ }^{a}$ Faculty of Biomedical Engineering, Czech Technical University in Prague, Nám. Sítná 3105, 272 01 Kladno, \\ Czech Republic \\ ${ }^{b}$ Cardiovascular Center, Na Homolce Hospital, Roentgenova 2/37, 15030 Prague, Czech Republic \\ * corresponding author: svitlana.strunina@fbmi.cvut.cz
}

\begin{abstract}
The flow-dependent left ventricle overload is a well-known complication of the veno-arterial extracorporeal membrane oxygenation in a severe cardiogenic shock, which leads to a distension of the left ventricle and, frequently, to a severe pulmonary edema. Recently, an unloading of the left ventricle using a catheter inserted to the left ventricle and connected to the extracorporeal membrane oxygenation circuit has been proposed. The computational method was used to simulate the blood flow in the extracorporeal membrane oxygenation system with a drainage catheter incorporated to the left ventricle and connected to the inflow part of the extracorporeal membrane oxygenation circuit by a Y-shaped connector. The whole system was modelled in Modelica modelling language. The impact of various catheter sizes (from $5 \mathrm{Fr}$ to $10 \mathrm{Fr}$ ) and extracorporeal blood flow values (from $1 \mathrm{~L} / \mathrm{min}$ to $5 \mathrm{~L} / \mathrm{min}$ ) were investigated.

In our simulation model, the extracorporeal blood flow only modestly affected the value of volume that was withdrawn from the left ventricle by a catheter. Conversely, the size of the drainage catheter was the principal factor responsible for the achievement of the adequate left ventricle decompression. A 10 Fr drainage catheter, inserted into the left ventricle and connected to the venous part of the ECMO system, presents a promising solution to the unloading of the left ventricle during a extracorporeal membrane oxygenation.
\end{abstract}

KEYWORDS: catheter; decompression; extracorporeal membrane oxygenation; mathematical modeling; Modelica modeling language; overload.

\section{INTRODUCTION}

The heart function improvement following a cardiac support was reported early [1]. The veno-arterial extracorporeal membrane oxygenation (VA-ECMO) currently represents the most effective minimally invasive circulatory support system. The VA-ECMO provides a sufficient support to enable an adequate tissue perfusion even in the case of cardiac arrest. However, a marked increase in systemic blood pressure caused by the VA-ECMO may also impair the function of the left ventricular (LV). In the presence of a severe left ventricle dysfunction, the left ventricle is unable to eject a sufficient blood volume, this leads to the increased afterload caused by the extracorporeal membrane oxygenation blood flow (EBF) and, consequently, to an impairment of the LV performance. In the extreme situation, the aortic valve remains closed even during systole. This results in the LV overload with distension, increased wall stress and increased myocardial oxygen consumption [2]. Insufficient decompression of the left ventricle during the VA-ECMO is considered as a major factor preventing an adequate $\mathrm{LV}$ recovery 3. Several methods are used for the LV decompression during the VA-ECMO therapy: a surgical approach with a minimally invasive thoracotomy, percutaneous approaches via the pulmonary artery or aortic valve, or through a septostomy, percutaneously inserted microaxial pump or intraaortic balloon pump. The LV decompression, during the ECMO therapy, seems to be associated with a significant improvement of the LV function [4]. The left ventricle can be unloaded by an insertion of a pigtail catheter into the LV through the aortic valve and connected to the inflow line of the ECMO circuit by an Y-shaped connector [2]. Figure 1 shows the unloading method during the ECMO therapy by the catheter inserted in the LV. There is a lack of information about the impact of the drainage catheter diameter and extracorporeal blood flow value on the LV decompression by the catheter inserted in the LV. The main objective of this study is to assess the unloading capacities of various diameters of the drainage catheter and various $\mathrm{EBF}$ values. Modelica modelling language was employed to identify the association between the catheter diameter and volume value withdrawn from the left ventricle in a big animal model with cardiogenic shock during the ECMO and, consequently, to evaluate the effect of the catheter diameter on the LV unloading. Modelica language is an object oriented, hierarchical, equation based and acausal modeling language, in which models can be created and graph- 


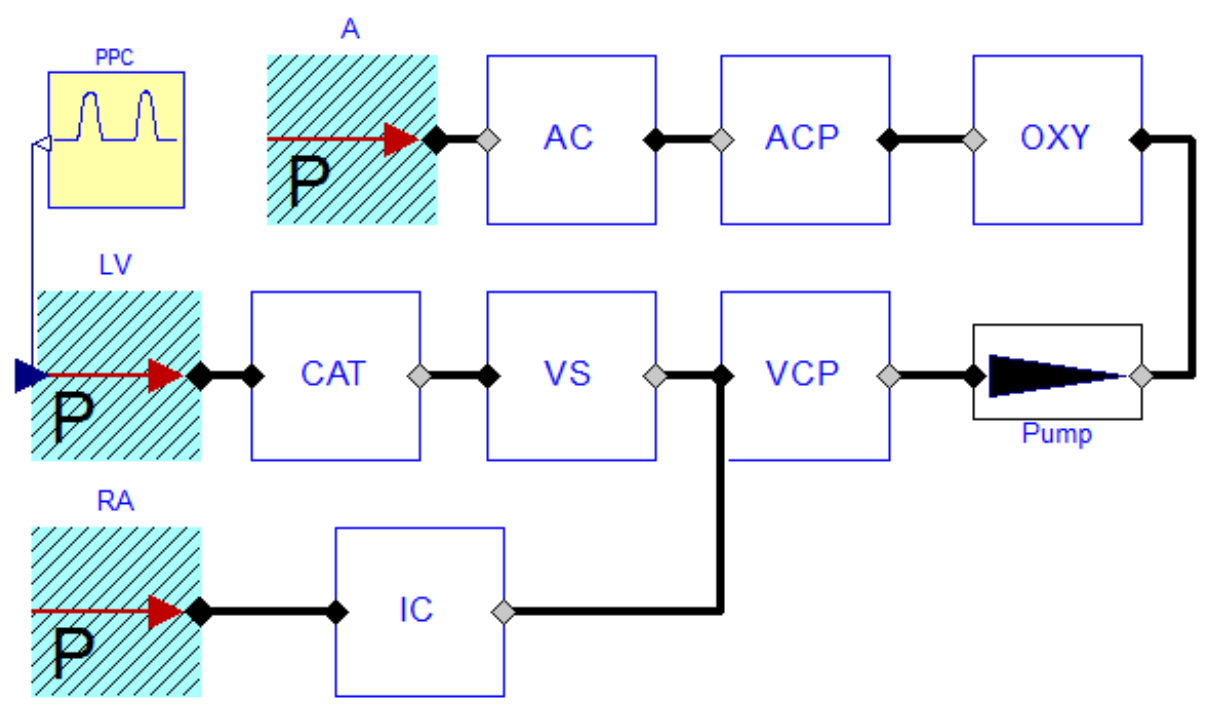

Figure 2. System diagram. PPC - pulses pressure change, LV - left ventricle, RA - right atrium, CAT - vent, VS volume sensor, VCP - venous circuit part, OXY - oxygenator, ACP - arterial circuit part, AC - arterial cannula, A aorta, IC - inflow cannula.

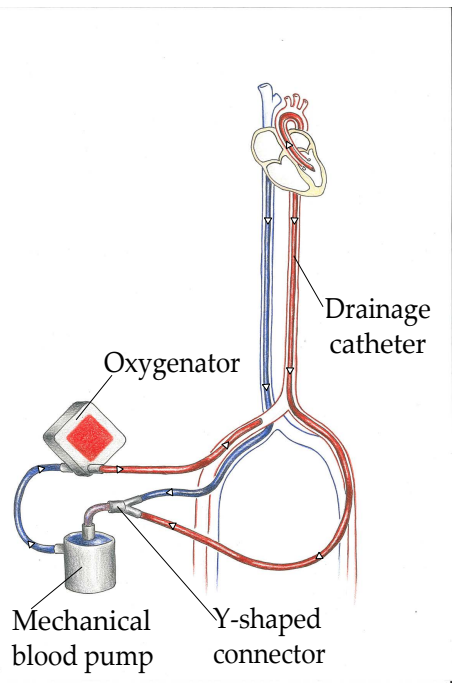

FIGURE 1. Unloading method during ECMO therapy by catheter.

ically represented from pre-prepared components or by connecting instances of classes from libraries [5, 6. Modelica language is acausal, which means that the equations can be expressed declaratively and the Modelica tool determine which of variables are dependent and independent based on the context upon a compilation [7]. The models are prepared to simulate just by a simple setting of the parameters. In the result of the simulation, the user can examine the change of variable values over time [6]. The main problem of medical research, articles, and experiments is using obscure units from medicine, pharmacology, biology and non-physics disciplines. One of the advantages of the Modelica environment is the support of non-SI units in the parameter dialog of each component. Values are represented by SI-units in the text code, but the Modelica environment supports non-SI units in the parameter dialog of each component. Physiological units are implemented as the displayUnits for each variable. Using displayUnits, the user can establish and observe the "physiological" values [8].

\section{MATERIALS AND METHODS}

In this study, a computer model was used to assess the LV unloading capacities of various diameters of drainage catheter inserted in the LV and EBF values.

\subsection{COMPUTER MODEL}

The whole system was modelled in Modelica modeling language, which uses a hierarchical object-oriented modelling. The model is described using the following compartments: left ventricle, right atrium, aorta, oxygenator, pump, tube set of ECMO system and integrated drainage catheter incorporated into the LV and connected to ECMO system (Figure 2). Each compartment is modelled using a mathematical relationship between blood volume $V_{i}(t)$, input flow rate $F_{i}(t)$ and output flow rate $F_{i \text {,out }}(t)$ relative to the ith compartment given as

$$
\frac{\mathrm{d} V_{i}(t)}{\mathrm{d} t}=F_{i}(t)-F_{i, \text { out }}(t)
$$

With a flow rate $F_{i j}(t)$ between compartments $i$ and $j$ defined in general by 9 ]

$$
F_{i j}(t)=\frac{P_{i}(t)-P_{j}(t)}{R_{i j}}, \quad j=i-1 .
$$

Analogous to Kirchhoff's current law, which is applied in the electrical domain, the law sum-to-zero is applied 


\begin{tabular}{lccccc}
\hline Extracorporeal blood flow [L/min] & 1 & 2 & 3 & 4 & 5 \\
\hline End-systolic volume (ESV) [mL] & $64 \pm 11$ & $70 \pm 11$ & $74 \pm 11$ & $78 \pm 12$ & $83 \pm 14$ \\
Systolic blood pressure (SBP) [mmHg] & $60 \pm 7$ & $72 \pm 7$ & $81 \pm 6$ & $89 \pm 7$ & $97 \pm 8$ \\
LV end-diastolic pressure (EDP) $[\mathrm{mmHg}]$ & $17.2 \pm 1.4$ & $18.2 \pm 0.7$ & $18.6 \pm 1.5$ & $18.9 \pm 2.4$ & $19.0 \pm 2.9$ \\
Heart rate (HR) & $94 \pm 4$ & $89 \pm 3$ & $84 \pm 3$ & $80 \pm 2$ & $77 \pm 2$ \\
\hline
\end{tabular}

TABLE 1. Initial values of state variables and parameters of the model in Modelica.
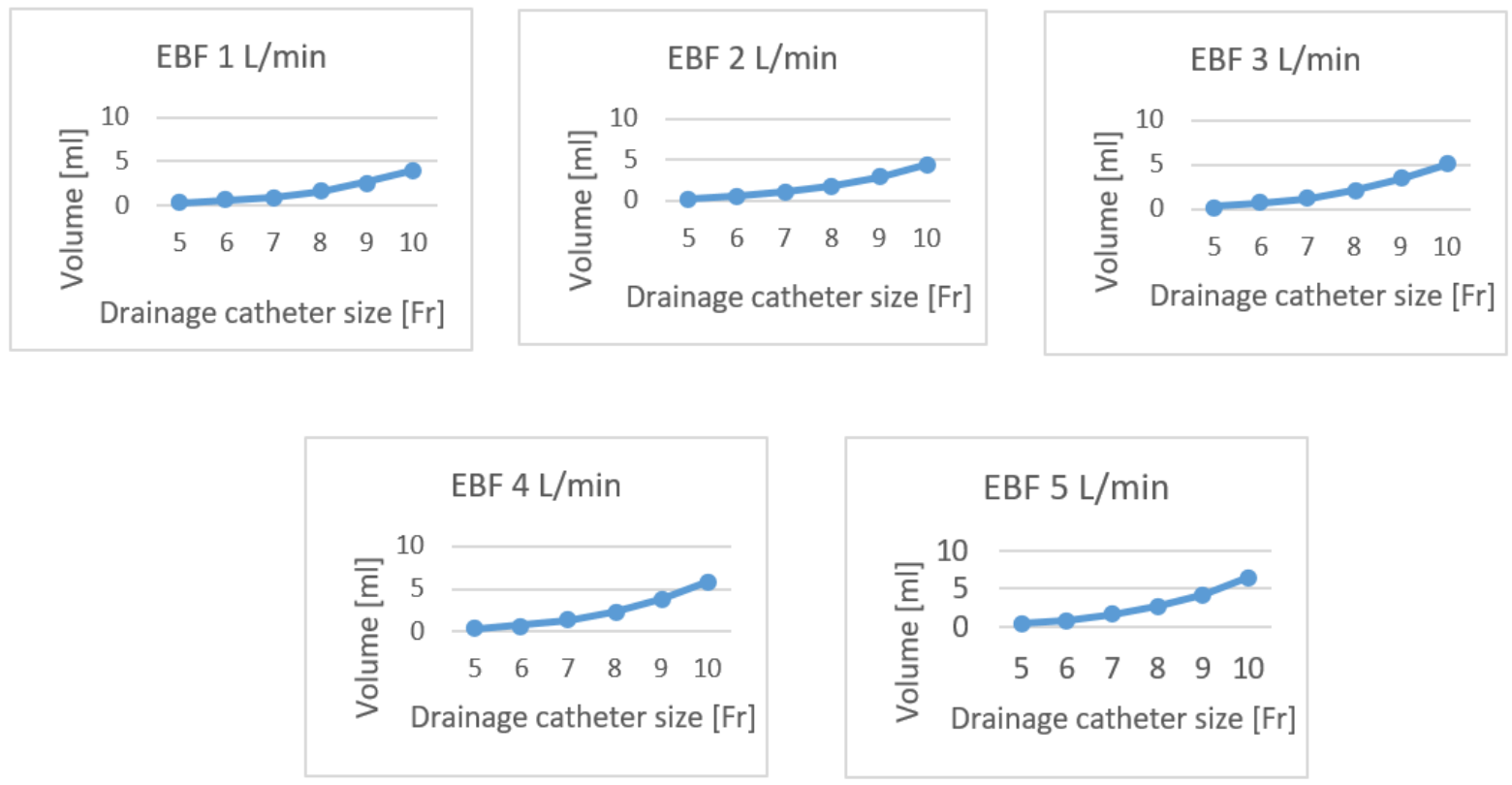

FigURE 3. Withdrawal volume value for cardiac cycle according to the catheter size. The values can be found in Table 2

in the hydraulic domain to the flow variables. The sum of all mass flows at any given point is zero [10]

$$
F_{\text {in }}-F_{\text {out }}=0 \text {. }
$$

The left ventricular pressures were established according to a single cycle of cardiac activity time given as 11

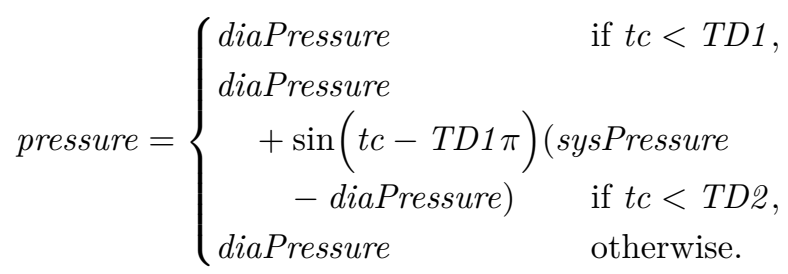

The blood flow in the system components can be completely described by Hagen-Poiseuille equation. The equation brings together all of the variables that determine flow

$$
Q=\frac{\pi \Delta \operatorname{Pr}^{4}}{8 \mu L}
$$

Hagen-Poiseuille equation states that the maximum flow is inversely proportional to the lumen length and directly proportional to the fourth power of the radius for a circular cross-section of lumen [12]. The radius and length of components were various, as a consequence of required quantities. The dynamic viscosity of blood 0.001 Pas was chosen [13].

The pump element was used from Modelica library for physiological calculations - Physiolibrary. For the simulation purpose, the pump flow rate was gradually increased from $1 \mathrm{~L} / \mathrm{min}$ to $5 \mathrm{~L} / \mathrm{min}$.

The oxygenator was modelled as a compartment with a pressure gradient.

$$
\Delta P=P_{\text {in }}-P_{\text {out }} .
$$

The simulation in this study is based on data from a standard in vivo experiment on large animal models. The initial parameter values were derived from measurements on a female swine [14. The parameters for the simulations are presented in Table 1 .

\subsection{Model OUtPut}

The output variables consisted of time-varying flow rate value and pressure in different parts of the ECMO circuit and time-varying volume value withdrawn from the LV. The values are presented in the following units: time-varying flow rate value in $\mathrm{ml} / \mathrm{s}$ and volume value withdrawn from the LV in $\mathrm{ml}$.

\subsection{Simulations}

For the simulation purpose, the pump volume flow rate was gradually increased from $1 \mathrm{~L} / \mathrm{min}$ to $5 \mathrm{~L} / \mathrm{min}$ 


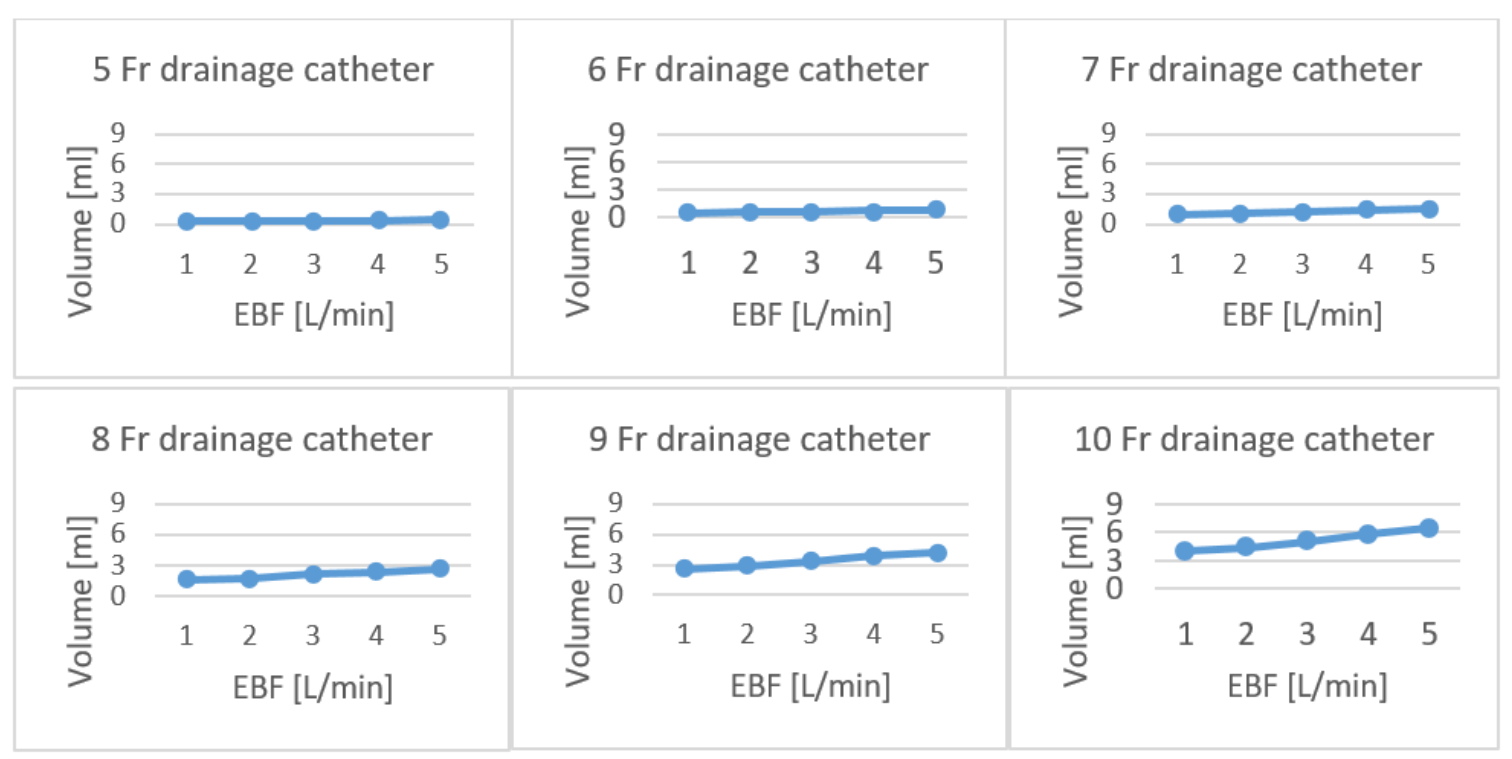

FIgURE 4. The effect of veno-arterial extracorporeal membrane oxygenation blood flow on withdrawal volume value for cardiac cycle. The values can be found in Table 2 .

(Table 2). For each value of the extracorporeal blood flow, the value of systolic blood pressure, the LV enddiastolic blood pressure and heart rate were changed in accordance with the obtained data from the experiment on big animal models. The internal diameter of the drainage catheter was gradually increased from 5 Fr to 10 Fr (Table 2 for a various EBF value. The entire process was done for each unique combination of the EBF, catheter size and vital parameters.

\section{RESUlts}

The conducted study indicates that the size of the drainage catheter is a crucial factor when the insertion of a pigtail catheter into the LV through the aortic valve is used as a method of the LV decompression during the ECMO therapy. Figure 3 depicts the withdrawal volume value for the cardiac cycle according to the catheter size. The results of the simulation have indicated that the EBF does not greatly affect the withdrawal volume value from the LV by drainage catheter. The relationship between the withdrawal volume value for the cardiac cycle and the EBF is shown in Figure 4

Figure 5 depicts the flow rate profiles throughout the cardiac cycles and the varying-in-time volume value withdrawn from the LV by the drainage catheter according to the catheter size. The red circles depict the volume values withdraw from the LV for a one cardiac cycle. Table 2 presents the simulation results of volume values withdrawn from the LV for a one cardiac cycle. The drainage catheter size ranges from $5 \mathrm{Fr}$ to $10 \mathrm{Fr}$, the $\mathrm{EBF}$ value varies from $1 \mathrm{~L} / \mathrm{min}$ to $5 \mathrm{~L} / \mathrm{min}$. The outcomes of the simulation have shown that the $10 \mathrm{Fr}$ drainage catheter withdraws $5.38 \pm 0.76$ ml during one cardiac cycle during the EBF from $1 \mathrm{~L} / \mathrm{min}$ to $5 \mathrm{~L} / \mathrm{min}$ (Table 2).

\begin{tabular}{cccccc}
\hline & \multicolumn{5}{c}{$\begin{array}{c}\text { Extracorporeal blood } \\
\text { flow EBF }[\mathrm{L} / \mathrm{min}]\end{array}$} \\
\cline { 2 - 6 } Drainage & 1 & 2 & 3 & 4 & 5 \\
\cline { 2 - 6 } catheter & \multicolumn{5}{c}{ Blood withdrawal } \\
size [Fr] & \multicolumn{5}{c}{ for cardiac cycle $[\mathrm{ml}]$} \\
\hline 5 & 0.25 & 0.27 & 0.32 & 0.36 & 0.41 \\
6 & 0.52 & 0.58 & 0.67 & 0.76 & 0.85 \\
7 & 0.96 & 1.06 & 1.24 & 1.41 & 1.56 \\
8 & 1.63 & 1.82 & 2.12 & 2.41 & 2.67 \\
9 & 2.63 & 2.90 & 3.37 & 3.84 & 4.26 \\
10 & 3.96 & 4.37 & 5.08 & 5.78 & 6.41 \\
\hline
\end{tabular}

TABLE 2. Volume rate value withdraw from LV during VA ECMO in Modelica.

\section{Discussion}

An increase of the LV afterload, together with severe systolic dysfunction during the VA-ECMO, often requires an urgent LV unloading. A number of sources mention that the drainage catheter is successfully used for the LV unloading during the ECMO therapy [3, 1620, but there is very little knowledge of the catheter size for an adequate LV unloading. This study was focused on the withdrawn blood volumes from the $\mathrm{LV}$ for a one cardiac cycle. One common complication of the ECMO is the LV overload and distention, primarily due to the increased afterload caused by the EBF 2]. The ECMO application causes an increase of end-systolic volume (ESV) and can induce deterioration of LV the function [1. The end-systolic volume is the amount of blood left in the ventricle at the end of the contraction [15. Therefore, the objective was to identify the appropriate size of the drainage catheter for the extraction of the excessive 


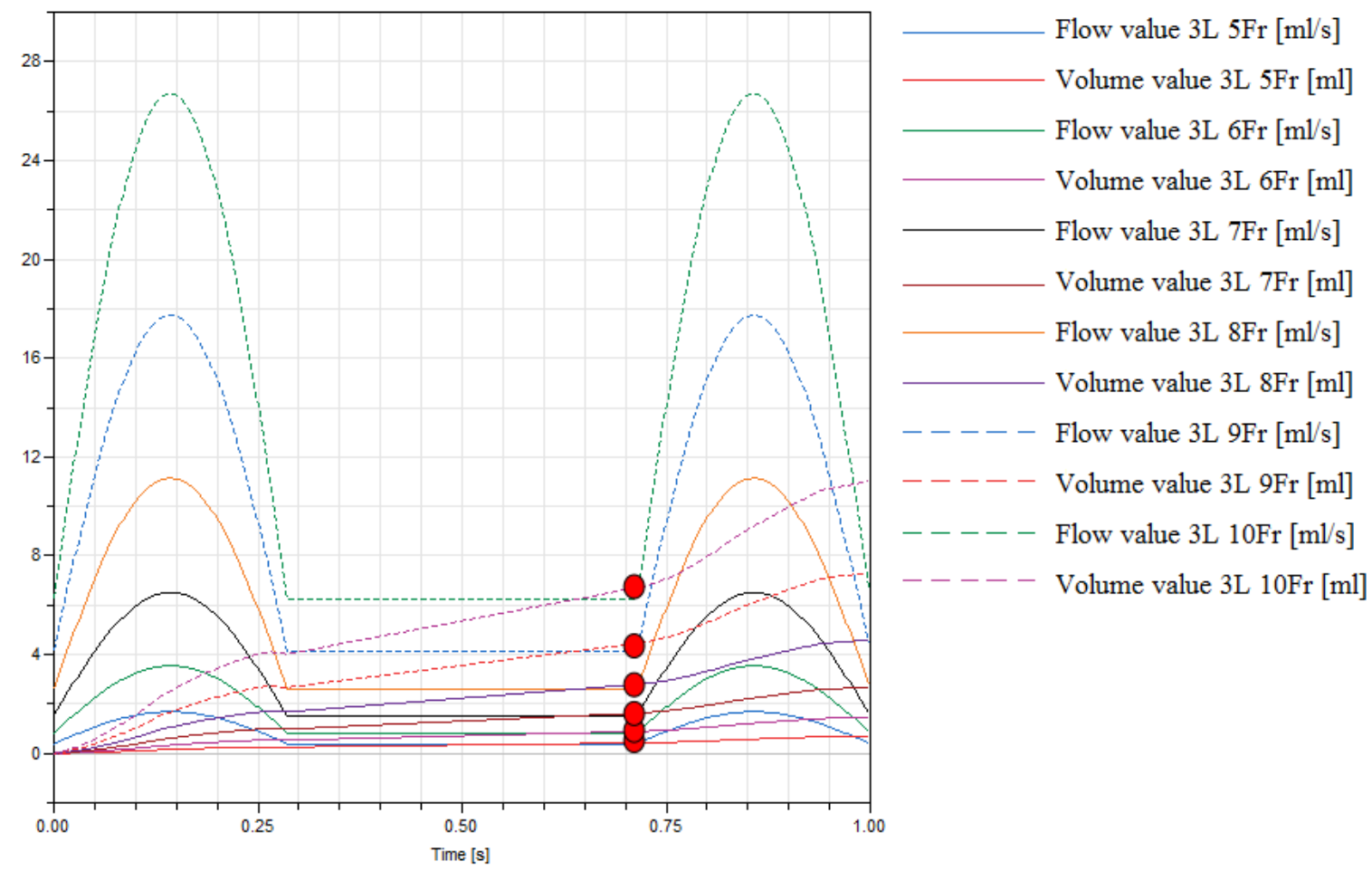

FiguRE 5. Flow rate profiles throughout the cardiac cycle and varying in time volume value withdraw from LV by drainage catheter, EBF $3 \mathrm{~L} / \mathrm{min}$.

ESV, to maintain adequate emptying of the LV at the end of each cardiac cycle, and thereby decompression of the LV during the ECMO. As you can see in Table 1. with an increase of the EBF from $1 \mathrm{~L} / \mathrm{min}$ to $5 \mathrm{~L} / \mathrm{min}$, the $\mathrm{LV}$ end-systolic volume increases, at average, to $4.75 \pm 0.95$ milliliters per liter (Table 1). The outcomes of the simulation have shown that the 10 Fr drainage catheter withdraws $5.38 \pm 0.76 \mathrm{ml}$ during one cardiac cycle during the EBF from $1 \mathrm{~L} / \mathrm{min}$ to $5 \mathrm{~L} / \mathrm{min}$ (Table 2). Thereby, the $10 \mathrm{Fr}$ catheter presents a promising solution to achieve the purpose of the LV unloading during the ECMO by a drainage catheter inserted in the LV and connected to the venous part of the ECMO system. The present study demonstrates that the withdrawal volume value by drainage catheter, connected to the inflow part of the ECMO system, depends mainly on the size of the catheter. The EBF did not demonstrate a notable effect. When the catheter diameter was kept constant and the EBF varied, the flow in the drainage catheter varied marginally. The limitations of the study are related to the mathematical model. Created model replicates the general specification of the flow in the ECMO circuit. The model does not completely behave the same way as the ECMO system. It has been assumed that blood is modelled as an incompressible, Newtonian fluid. The flow is considered to be laminar with no acceleration of the fluid in the ECMO circuit, gravitational effects were neglected. To make the study results clinically feasible, future work should be verified with the ECMO system specific model.

\section{Conclusions}

Unloading capacities of various drainage catheter diameters and various EBF values during the ECMO by applying a numerical method is presented in this paper. The results suggest that the catheter diameter is the crucial factor when an insertion of a pigtail catheter into the LV through the aortic valve is used as a method of the LV decompression during the ECMO therapy. The EBF hardly affects a withdrawal volume value by the drainage catheter from the LV. The model used in the presented work provides interesting answers to the question regarding determining parameters in the ECMO circuit. The model can predict details of the pressure, withdrawal volume and flow rate value at any position in the system throughout the cardiac cycles.

\section{LIST OF SYMBOLS}

$V_{i} \quad$ Blood volume $\left[\mathrm{m}^{3}\right]$

$F_{i, \text { in }}$ Input flow rate $\left[\mathrm{m}^{3} / \mathrm{s}\right]$

$F_{i, \text { out }}$ Output flow rate $\left[\mathrm{m}^{3} / \mathrm{s}\right]$

$F_{i j} \quad$ Flow rate between compartments $i$ and $j\left[\mathrm{~m}^{3} / \mathrm{s}\right]$

$P_{i} \quad$ Pressure of compartment $i[\mathrm{~Pa}]$

$P_{j} \quad$ Pressure of compartment $j[\mathrm{~Pa}]$

$R_{i j} \quad$ Resistance between compartments $i$ and $j$ $\left[\left(\mathrm{N} / \mathrm{m}^{2}\right)\left(\mathrm{m}^{3} / \mathrm{sec}\right)^{-1}\right]$

$F_{\text {in }}$ Input flow $\left[\mathrm{m}^{3} / \mathrm{s}\right]$

$F_{\text {out }}$ Output flow $\left[\mathrm{m}^{3} / \mathrm{s}\right]$

diaPressure Diastolic blood pressure $[\mathrm{Pa}]$

sysPressure Systolic blood pressure [Pa] 
tc Relative time in cardiac cycle [s]

TD1 Relative time of start of systole $[\mathrm{s}]$

TD2 Relative time of end of systole [s]

$Q$ Volumetric flow rate $\left[\mathrm{m}^{3} / \mathrm{s}\right]$

$\mu$ Dynamic viscosity [Pas]

$r$ Pipe radius $[\mathrm{m}]$

$L \quad$ Length of pipe [m]

$\Delta P$ Pressure reduction $[\mathrm{Pa}]$

$P_{\text {in }}$ Input pressure $[\mathrm{Pa}]$

$P_{\text {out }}$ Output pressure $[\mathrm{Pa}]$

\section{REFERENCES}

[1] S. Vandenberghe, P. Segers, B. Meyns and P. Verdonck. Unloading effect of a rotary blood pump assessed by mathematical modeling. Artif Organs 27(12), pp. 1094-101. 2003.

[2] S. Strunina and P. Ostadal, "Left ventricle unloading during veno-arterial extracorporeal membrane oxygenation", Current Research: Cardiology, vol. 3, pp. 5-8, 2016.

[3] Hong, Byun, Yoo, Hwang, Kim and Park. Successful left-heart decompression during extracorporeal membrane oxygenation in an adult patient by percutaneous transaortic catheter venting. The Korean Journal of Thoracic and Cardiovascular Surgery 48(3), pp. 210-213. 2015.

[4] G. Douflé, A. Roscoe, F. Billia and E. Fan, "Echocardiography for adult patients supported with extracorporeal membrane oxygenation", Critical Care, vol. 19, pp. 1-10, 2015.

[5] Ježek Filip et al, "Zkušenosti z inovace výuky modelování a simulace na FEL ČVUT." in 2012, pp. 139-146.

[6] M. Mateják, "Physiology in Modelica," MEFANET Journal, vol. 2, (1), pp. 10-14, 2014.

[7] T. Kulhánek et al, "Simple models of the cardiovascular system for educational and research purposes," MEFANET Journal, vol. 2, (2), pp. 56-63, 2014.

[8] Mateják Marek et al, "Physiolibrary — Modelica library for Physiology," (96), pp. 499-505, 2014.

[9] J. Fernandez de Canete, J. Luque, J. Barbancho and V. Munoz. Modelling of long-term and short-term mechanisms of arterial pressure control in the cardiovascular system: An object-oriented approach. Computers in Biology and Medicine 47pp. 104-112. 2014.
[10] P. Fritzson, Principles of Object-Oriented Modeling and Simulation with Modelica 3.3: A Cyber-Physical Approach. Wiley, 2014.

[11] T. Kulhánek, M. Tribula, J. Kofránek and M. Mateják. Simple models of the cardiovascular system for educational and research purposes. MEFANET Journal 2(2), pp. 56-63. 2014.

[12] K. Kohler, K. Valchanov, G. Nias and A. Vuylsteke, "ECMO cannula review," Perfusion, vol. 28, pp. 114-124, 2013.

[13] B. Uggla and T. K. Nilsson, "Whole blood viscosity in plasma cell dyscrasias," Clin. Biochem., vol. 48, pp. 122-124, 2015.

[14] Ostadal, Mlcek, Kruger, Hala, Lacko, Mates, Vondrakova, Svoboda, Hrachovina, Janotka, Psotova, Strunina, Kittnar and Neuzil. Increasing venoarterial extracorporeal membrane oxygenation flow negatively affects left ventricular performance in a porcine model of cardiogenic shock. Journal of Translational Medicine 13(1), 2015.

[15] D. U. Silverthorn, B. R. Johnson, W. C. Ober, C. W. Garrison and A. C. Silverthorn, Human Physiology: An Integrated Approach. Pearson Education, 2013.

[16] H. Kurihara, M. Kitamura, M. Shibuya, Y. Tsuda, M. Endo and H. Koyangi, "Effect of Transaortic Catheter Venting on Left Ventricular Function During Venoarterial Bypass," ASAIO Journal, vol. 43, 1997.

[17] M. Kitamura, K. Hanzawa, M. Takekubo, K. Aoki and J. Hayashi. Preclinical assessment of a transaortic venting catheter for percutaneous cardiopulmonary support. Artificial Organs 28(3), pp. 298-302. 2004.

[18] M. Guirgis, K. Kumar, A. H. Menkis and D. H. Freed. Minimally invasive left-heart decompression during venoarterial extracorporeal membrane oxygenation: An alternative to a percutaneous approach. Interact CardioVasc Thorac Surg 10(5), pp. 672-674. 2010.

[19] Barbone A, Malvindi PG, Ferrara P, et al. Left ventricle unloading by percutaneous pigtail during extracorporeal membrane oxygenation. 13(3), pp. 293-295. 2011.

[20] T. H. Hong, J. H. Byun, H. M. Lee, Y. H. Kim, G. Kang, J. H. Oh, S. W. Hwang, H. Y. Kim and J. H. Park, "Initial Experience of Transaortic Catheter Venting in Patients with Venoarterial Extracorporeal Membrane Oxygenation for Cardiogenic Shock," ASAIO Journal, vol. 62, 2016. 